Stanisław PIWOWARCZYK

\title{
NARCOSIS INDUCED IN EUROPEAN BISON BY MEANS OF CHLORAL HYDRATE AND ETHYL ALCOHOL
}

NARKOZA U ŻUBROW PRZY POMOCY WODNIKA CHLORALU I ALKOHOLU ETYLOWEGO

\section{Bisoniana $\mathbf{X X X}$}

Experiments were made on inducing narcosis in European bison by means of chloral hydrate and alcohol. Fifteen animals were used for the experiments, on one of which tests were made at different intervals of time, using chloral hydrate and alcohol separately. The best results were obtained by oral administration, first of chloral hydrate and then 15-20 minutes later, alcohol. The dose of chloral hydrate for one animal was accepted as from $7-20 \mathrm{~g}$ per $50 \mathrm{~kg}$ of body weight, and from $600-$ $700 \mathrm{~g}$ of alcohol for one animal. Duration of narcosis varied from a few minutes to 4 hours. This method of inducing narcosis in European bison can be used in order to carry out prophylactic operations, for facilitating transport and for surgical operations, but it cannot be used in sudden emergencies for technical reasons.

It has proved necessary, in connection with the prophylactic inoculation of European bison and also the reduction of these animals to a passive state in order to transport them, to carry out experiments on inducing narcosis in these animals. In view of the size and strength of this species, and its wildness, our present state of knowledge permits of administering the narcotoc either via the alimentary tract or by means of a Palmer's capture gun. The preparation used to induce narcosis by oral administration, to be taken by the animal in fluid form, must guarantee a certain degree of safety of the animal during narcosis. It cannot have properties rendering it nauseous to the animal (taste, smell). It must be easily soluble in water. We considered chloral hydrate as the preparation best meeting our requirements. This is a narcotic easily obtainable, cheap and taken by the animals with relatively little difficulty. It is rapidly resorbed by the mucous membrane of the alimentary tract. In the blood it is converted to trichloroethane, to which narcotic properties are attributed. A great advantage of this preparation is that the stage of excitement in ruminants during narcosis lasts a very short time. Its drawback is that the dividing line between the narcotic dose of $5-6 \mathrm{~g}$ per $50 \mathrm{~kg}$ of body weight, and the lethal dose of $10-15 \mathrm{~g} / 50 \mathrm{~kg}$ is relatively narrow, which in the case of wild animals, whose weight is usually estimated visually, may be of fundamental importance. Death takes place as the result of paralysis of the respiratory system. Care should therefore be taken to avoid giving maximum doses. The effects of complete narcosis include a very long period of post-narcotic sleep.

When administered orally the animals should be previously prepared by depriving them of water to drink for $1-2$ days, and adding a little sodium chloride to their [Acta theriol., 12, 32: 467, 1967] 
food in order to increase thirst. The preparation should be given in a water solution with the addition of infused linseed.

In cattle under chloral hydrate anaesthesis the movements of the rumen can be seen to be slowed down, which with complete narcosis may sometimes lead to bloat of the rumen and to aspiratory pneumonia. The recommended dose per animal is $4-5 \mathrm{~g} / 50 \mathrm{~kg}$ of body weight.

Ethyl alcohol can be used to intensify the effect of other narcotics. Alcohol may in principle cause only stupefaction, but does not induce true narcosis. It is used in cases in which it is impossible to use another preparation.

Alcohol effects the central nervous system, causes weakening of reflexes, eliminates muscular coordination, expands the peripheral vessels, and reduces temperature. The dose for cattle per os is about $400 \mathrm{ml}$.

Chloral hydrate and ethyl alcohol for tests of narcosis induced in European bison were used, the experiments being made first using one and the other preparation separately, in order to ascertain their effect on the animals' organism.

The experiments were made on 15 male bison of varying ages, from 2 to 7 years old. The animals examined were in good health and condition and their weight, depending on age, was from 250 to $750 \mathrm{~kg}$. On account of the lack of relative literature during the first tests the doses given to cattle were taken as a guide, administering $5 \mathrm{~g}$ of chloral hydrate per $50 \mathrm{~kg}$ of body weight of the animal and $400 \mathrm{~g}$ of $96 \%$ ethyl alcohol per animal. The doses adapted to the weight of the animals and given with water did not cause any visible effect.

It must be emphasised that at first the preparation of the animals for the dose of narcotic in water proved somewhat difficult. Despite their being deprived of food and water for 3 days, they consumed the preparation reluctantly. After a few tests had been made it proved that they most readily accept the narcotic after being deprived of water for 48 hours and food for 24 hours. Both the preparations were then readily consumed in $10 \%$ solutions. When given in greater concentrations they were either not consumed or only consumed in small amounts.

The experiments using alcohol on the male European bison "Puszkarz", aged about 2 years, weight about $240 \mathrm{~kg}$, were made four times at intervals of time making cumulation of the preparation impossible (period 3-4 weeks), the doses of alcohol given being 900, 1250, 1500 and $1800 \mathrm{ml}$. The manifestations of the effect of the alcohol appeared within 10-15 minutes in the form of stupefaction, staggering, unrest, stumbling, falling over and even lying down for a time. Respiration is accelerated. After an hour the manifestations of the effect of preparation disappeared and the animal quickly returned to its normal state. The symptoms increased only very slightly when the dose of alcohol was increased. We did not succeed in inducing complete narcosis by means of alcohol. The case described above justifies the conclusion that the dose sufficient to stupefy this animal is about $1200-1500 \mathrm{ml}$.

The same male bison was used for the tests with chloral hydrate, which was administered in a decoction of linseed, of course at a different time from the above tests. Doses of $70,80,90$ and $100 \mathrm{~g}$ were given. The manifestations of the effect of chloral hydrate appeared within $20-30$ minutes, in the form of drowsiness, staggering, stumbling and swaying 
of the hindquarters. The animal laid down normally. Symptoms of excitement occurred to a minimum degree only and that rarely. Chloral hydrate also failed to produce the complete narcosis making it possible to inject the animal, since despite the latter's drowsiness it did not allow humans to approach it. When this was attempted the animal quickly got up and made its escape. Under these circumstances it was decided to attempt to produce narcosis by the combined use of chloral hydrate and alcohol.

The experimental procedure was as follows:

After first depriving it of water for 2 days and food for 24 hours, the European bison "Puszkarz" was given $100 \mathrm{~g}$ of chloral hydrate in 10 litres of linseed decoction at 11 o'clock. It drank the chloral hydrate within 25 minutes and 20 minutes later the first manifestations of stupefaction appeared (wavering walk, stumbling). It readily ate the hay offered it. At 12.00 it was given $600 \mathrm{~g}$ of $96 \%$ alcohol diluted in well water to $10 \%$. The stupefied animal readily drank the liquid, but after finishing the last draught at 12.20 it fell back on its hindquarters and then fell over on to its left side. During the first 10 minutes the animal reacted to being touched by the hand or pricked with a needle, but after 10-12 minutes it exhibited no reaction. The head was thrown backwards, limbs straight, eyelids closed, profound respiration, $11 / \mathrm{min}$, weak reflex of cornea and pupil. The animal lay unconscious until 16.30. At 16.30 it woke up but despite its efforts could not stand up. It was not until 17.20 that the animal got up of its own accord without any stimulus from the experimenters. While walking it was observed still to be shaky on its legs, but this gradually disappeared. During the period of narcosis it did not react to pricking with a needle, or to manipulations in the region of the nose, mouth and eye. Complete narcosis lasting about 4 hours was therefore achieved. This state permits not only of making injections but also performing important surgical operations.

The European bison "Pukacz" weighing about $270 \mathrm{~kg}$ was given similar narcosis treatment except that the dose of chloral hydrate was slightly greater, i.e. $110 \mathrm{~g}$ on account of its greater body weight. As in the preceeding case, narcosis occurred within $20-30$ minutes, but the animal's position was different, since it lay on its sternum, with the mucosae resting on the ground. Narcosis lasted only 1 hour 10 minutes in this case, but during narcosis the animal did not react to external stimuli.

A further 13 animals weighing from $250-750 \mathrm{~kg}$ were subjected to narcosis, with good results, but duration of narcosis differed from several minutes to $3-4$ hours. The time was therefore sufficient to carry out a small operation such as injection, and occasionally a surgical operation.

In my opinion duration of narcosis in different individuals depended to a great extent on adapting the dose of the preparation given to body weight, and on the susceptibility of the different animals to the preparations used, on the rate at which it is drunk, the amount of rumen contents, the weather conditions, the individual condition of the animals etc.

The dose of chloral hydrate used to produce narcosis in the 15 individuals of European bison observed was from 7 to $20 \mathrm{~g}$ per $50 \mathrm{~kg}$ of body weight, but the dose of $110 \mathrm{~g}$ per animal was never exceeded. The 
limitation of the dose of chloral hydrate was due to the necessity for limiting the amount of water given to the animal, as after drinking more than 10 litres of $10 \%$ water solution of chloral hydrate it did not want to continue dringing the alcohol solution given it and moved away from the trough. On the other hand the animal's thirst was not quenched by drinking a smaller amount of the chloral hydrate solution. After the symptoms of stupefaction had appeared the animal readily drank the alcohol given it even in large quantities. The symptoms described by Westhues \& Fritsch (1961), which occurred after the above preparations had been administered to cattle, were not observed, that is, sudden excitement, frenzy similar to rabies, increased sex urge, turgidity of the rumen, vomiting reflexes. Symptoms were limited only to a very slight degree of excitement and to the animals' staggering, stumbling and even falling over.

Narcosis produced by means of chloral hydrate and alcohol can be applied to European bison in order to perform different operations, from injections to more complicated surgical operations.

A disadvantage of this method is the necessity for depriving the animals of water for at least 48 hours and of food for 24 hours, which involves isolating the animal from the herd. This method cannot therefore be used in sudden emergencies.

I should like to express my gratitude to the Director of the Nature Conservancy Office, Dr. T. Szczęsny and to ing. A. Jaroński, for their help in obtaining animals for the experiments and with transport arrangements.

\section{REFERENCES}

Bolz W., 1966: Allgemeinnarkoze beim Tier. Ferdinania Eule Verlag: 153-169; 237-238. Stuttgart. W esthues M. \& Frits ch R., 1961: Die narkose der Tiere. Parey Verlag: $100-104 ; 108-110$. Berlin und Hamburg.

Received, March 13, 1967.

Dept. Epizootiol., Warsaw Agric. Univ., Warszawa, Grochowska 272. 